IN PRACTICE

\title{
Patient, provider, and clinic characteristics associated with public STD clinic patient satisfaction
}

\author{
S D Mehta, J M Zenilman, E J Erbelding
}

Sex Transm Infect 2005;81:150-154. doi: 10.1136/sti.2003.009001

See end of article for authors' affiliations

Correspondence to Supriya Mehta, Dowling 1 South, Room 1334, 1 Boston Medical Center Place, Boston, MA 02118, USA; supriya.mehta@bmc. org

Accepted for publication 3 July 2004
Objectives: There is a lack of information describing levels of patient satisfaction among patients seeking sexually transmitted diseases (STD) care in a public clinic setting. We sought to identify patient, provider, and clinic characteristics associated with patient satisfaction within public STD clinics.

Methods: A cross sectional survey with random sampling was conducted among patients attending two public STD clinics. Satisfaction was assessed using questions from validated national surveys. Outcomes for multivariate logistic regression analysis were ratings of overall health care and clinician.

Results: 499/605 (82\%) patients were enrolled. Patients were mean age 29 years, $51 \%$ male, $94 \%$ black. Lower rating of clinician technical skills $(O R=15.6$ clinic $A, O R=7.9$ clinic $B)$ and clinic environment (OR $=3.9$ clinic $A, O R=9.6$ clinic $B$ ) were associated with lower healthcare rating, as was lower rating of television/video in waiting room $(O R=10.2$, clinic $A)$ and dysuria $(O R=4.2$, clinic $B)$. Higher clinician rating $(O R=0.58$, clinic $A)$ and receiving written materials $(O R=0.44$, clinic $B)$ were protective of lower healthcare rating. Risks for lower clinician rating at clinic $A$ were greater pain, problems getting care, lower rating of clinician technical skill, and overall health care, while receiving written materials was protective. At clinic B, lower rating of clinician technical skill and clinic environment were risks for lower clinician rating.

Conclusions: Patient satisfaction was associated with modifiable provider and clinic characteristics. Results from our study indicate a need to examine whether health outcomes of STD management vary by patient satisfaction.
S tudies of chronic disease outcomes have related patient satisfaction with care to better adherence to self care preventative practices and improved surrogate laboratory measures associated with better health outcomes. ${ }^{1-6}$ Decreased adherence to STD treatment can result in treatment failure with persistent infection and re-infection. ${ }^{78}$ Effective strategies to prevent further STD transmission and re-infection of the index patient, such as partner notification and referral, require a high level of cooperation by the patient and may be similarly influenced by satisfaction with clinical care delivered.

There are few data describing levels of patient satisfaction among patients seeking care in public clinic settings. We sought to describe the level of patient satisfaction at two public STD clinics with widely used standardised inventories, and to assess patient, provider, and clinic characteristics associated with decreased patient satisfaction.

\section{MATERIALS AND METHODS}

Population, study sample, and description of setting We conducted a prospective, cross sectional survey of patients seeking STD services at two public STD clinics. Patients attend the clinics on a "walk-in, first come, first served" basis and are assigned an appointment time for that day as they register. Review of clinic census shows patients to be median age 29 years, $97 \%$ and $92 \%$ African-American, and 54\% and $60 \%$ male (clinic A and clinic B, respectively). Clinics are staffed by mid-level practitioners (physicians' assistants or nurse practitioners) supervised on site by consulting physicians. All clinical services and laboratory testing are provided free of charge.

Recruitment occurred Monday through Friday, with even representation of days of the week and morning (8 $30 \mathrm{am}$ to $12 \mathrm{pm}$ ) and afternoon sessions ( $1 \mathrm{pm}$ to $5 \mathrm{pm}$ ), to avoid oversampling times of higher clinic volume and longer waiting times. A random sample of consecutive patients were approached and offered enrolment if aged 14 or older, English speaking, and undergoing a full clinical evaluation. Patients attending the clinic for HIV testing only were not approached for study enrolment (4.4\%).

Written informed consent was obtained. No personal identifiers or diagnosis was entered onto the survey form. The study was approved by the institutional review boards by participating agencies. Participants received a gift valued at $\$ 5$ for their time and effort.

\section{Data collection}

A research assistant (non-clinic staff) interviewed patients after seeing the clinician using a closed ended questionnaire. Data collected included age, sex, race, education completed, health insurance status, estimated distance from primary residence to clinic, and previous visits to the clinics and overall satisfaction at the last visit. Symptoms were assessed using a brief version of the clinic assessment, and modified questions from the SF-36. ${ }^{9}$ Pain was rated on a scale of 1 ("no pain at all") to 10 ("worst pain possible" ). ${ }^{10}$ Satisfaction was assessed using 11 questions modified from the CAHPS Study 2.0 Adult Core Questionnaire, ${ }^{11}$ and three questions from the Patient Visit Rating Questionnaire (VRQ, Medical Outcomes Study) ${ }^{12}$ (table 1). Data were abstracted from the medical record to obtain date and time, time seen by clinician, discharge time, STD history, medications, physical examinations performed, specimens obtained and site, and referrals received.

\section{Data analysis}

Data were analysed using Stata 7.0 for Windows (Stata Corporation, College Station, TX, USA). We tested associations

Abbreviations: STD, sexually transmitted diseases 


\begin{tabular}{|c|c|c|c|}
\hline & \multirow{2}{*}{$\begin{array}{l}\text { Clinic A } \\
\text { No (\%) }\end{array}$} & \multirow{2}{*}{$\begin{array}{l}\text { Clinic B } \\
\text { No (\%) }\end{array}$} & \multirow[b]{2}{*}{ p Value } \\
\hline & & & \\
\hline \multicolumn{4}{|l|}{ Patient characteristics } \\
\hline Education $\geqslant$ high school/GED & $191(65 \%)$ & $141(68 \%)$ & 0.417 \\
\hline Lives within 10 blocks of clinic & $89(30 \%)$ & $60(29 \%)$ & 0.802 \\
\hline Has health insurance (private or public) & $82(28 \%)$ & $62(31 \%)$ & 0.477 \\
\hline \multicolumn{4}{|l|}{ Main reason for visit } \\
\hline Check up (STD test) & $137(46 \%)$ & $109(53 \%)$ & \\
\hline Follow up visit & $21(7 \%)$ & $13(6 \%)$ & \\
\hline Symptoms & $95(32 \%)$ & 64 (31\%) & \\
\hline STD contact & $42(14 \%)$ & $19(9 \%)$ & 0.295 \\
\hline Has any symptoms & $212(72 \%)$ & $142(69 \%)$ & 0.478 \\
\hline Pain score $>1$ & $79(37 \%)$ & $55(29 \%)$ & 0.077 \\
\hline Previous visit to clinic $A$ or clinic $B$ & 215 (73\%) & $150(75 \%)$ & 0.577 \\
\hline Previous STD history & $239(81 \%)$ & $147(72 \%)$ & 0.015 \\
\hline \multicolumn{4}{|l|}{ Healthcare service delivery } \\
\hline Office staff treated you with courtesy & $266(100 \%)$ & $198(97 \%)$ & 0.003 \\
\hline Office staff were helpful & $292(99 \%)$ & 197 (97\%) & 0.058 \\
\hline Doctor or clinician gave written materials & $172(65 \%)$ & $112(55 \%)$ & 0.011 \\
\hline \multicolumn{4}{|l|}{ Visit characteristics } \\
\hline Mean waiting time (minutes) & $\begin{array}{l}127 \\
95 \% \mathrm{Cl}: 117 \text { to } 136\end{array}$ & $\begin{array}{l}92 \\
95 \% \text { Cl: } 82 \text { to } 103\end{array}$ & $<0.001$ \\
\hline Mean total visit time (minutes) & 174 & 140 & $<0.001$ \\
\hline & $95 \%$ Cl: 164 to 184 & $95 \% \mathrm{Cl}: 125$ to 151 & \\
\hline Received medications & $188(64 \%)$ & $144(71 \%)$ & 0.110 \\
\hline Had cervical or urethral specimens & $256(88 \%)$ & 189 (93\%) & 0.073 \\
\hline Had rectal examination and specimen & $10(3 \%)$ & $7(3 \%)$ & 0.986 \\
\hline Oral specimen & $96(33 \%)$ & $56(27 \%)$ & 0.215 \\
\hline Had blood drawn & $255(87 \%)$ & $158(77 \%)$ & 0.007 \\
\hline \multicolumn{4}{|l|}{ Patient satisfaction measures } \\
\hline \multicolumn{4}{|l|}{ Rate doctor or clinician " $0^{\prime \prime}-" 10^{\prime \prime}$} \\
\hline 10 & $174(59 \%)$ & $117(57 \%)$ & \\
\hline $7-9$ & $103(35 \%)$ & 79 (39\%) & \\
\hline $4-6$ & $15(5 \%)$ & $7(4 \%)$ & \\
\hline $0-3$ & $3(1 \%)$ & $1(0 \%)$ & 0.637 \\
\hline \multicolumn{4}{|l|}{ Technical skills of clinician } \\
\hline Poor & $0(0 \%)$ & $1(0 \%)$ & \\
\hline Fair & $14(5 \%)$ & $3(1 \%)$ & \\
\hline Good & $54(18 \%)$ & $25(12 \%)$ & \\
\hline Very good & $96(33 \%)$ & $50(25 \%)$ & \\
\hline Excellent & $131(44 \%)$ & $125(61 \%)$ & 0.002 \\
\hline \multicolumn{4}{|l|}{ Convenience of location of clinic } \\
\hline Poor & $3(1 \%)$ & $5(2 \%)$ & \\
\hline Fair & $18(6 \%)$ & $16(8 \%)$ & \\
\hline Good & $82(28 \%)$ & $51(25 \%)$ & \\
\hline Very good & $87(29 \%)$ & $37(13 \%)$ & \\
\hline Excellent & $105(36 \%)$ & $95(47 \%)$ & 0.015 \\
\hline \multicolumn{4}{|c|}{ Cleanliness/comfortableness of waiting area and treatment rooms } \\
\hline Poor & $2(1 \%)$ & $3(1 \%)$ & \\
\hline Fair & 32 (11\%) & $18(9 \%)$ & \\
\hline Good & 90 (31\%) & $49(24 \%)$ & \\
\hline Very good & $94(32 \%)$ & $59(29 \%)$ & \\
\hline Excellent & $77(26 \%)$ & $75(37 \%)$ & 0.095 \\
\hline \multicolumn{4}{|l|}{ Television and videos in waiting room } \\
\hline Poor & $38(13 \%)$ & $62(42 \%)$ & \\
\hline Fair & $42(15 \%)$ & 21 (14\%) & \\
\hline Good & 98 (34\%) & $27(18 \%)$ & \\
\hline Very good & $57(20 \%)$ & $14(10 \%)$ & \\
\hline Excellent & $52(18 \%)$ & $22(15 \%)$ & $<0.001$ \\
\hline \multicolumn{4}{|l|}{ Overall healthcare received today } \\
\hline Poor & $1(0 \%)$ & $1(0 \%)$ & \\
\hline Fair & $10(3 \%)$ & $4(2 \%)$ & \\
\hline Good & $54(18 \%)$ & $28(14 \%)$ & \\
\hline Very good & $84(29 \%)$ & $61(30 \%)$ & \\
\hline Excellent & $145(49 \%)$ & $110(54 \%)$ & 0.546 \\
\hline Would come back to this clinic & 295 (100\%) & 203 (100\%) & 0.229 \\
\hline
\end{tabular}

using Pearson's $\chi^{2}, t$ test, and logistic regression. Satisfaction measures were dichotomised for statistical analysis into "poor, fair, or good" versus "very good or excellent." Overall clinician rating was scored " 0 " (worst possible) to " 10 " (best possible) and analysed as a continuous independent variable, and dichotomised for outcome analysis. Logistic regression analysis outcomes were: (1) overall rating of health care "poor, fair, or good", and (2) clinician rating "less than 10." Median pain score was " 1 " and was dichotomised for analysis. All variables significant at the $\mathrm{p}<0.05$ level by univariate analysis were entered for multivariate logistic regression analysis, with 
Table 2 Results of multivariate analysis: factors associated with rating of overall health care less than "very good"

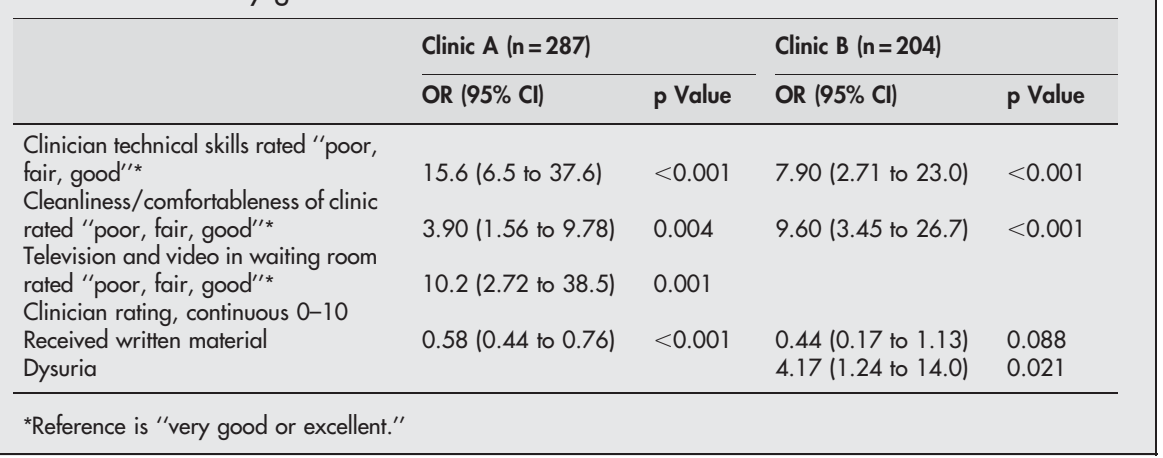

stepwise backwards likelihood ratio testing for model selection.

\section{RESULTS}

\section{Patient characteristics}

From October 2002 to February 2003, 378 patients were approached at clinic A, 295 (78\%) of whom participated. Participants were mean age 30.5 years, $56.6 \%$ male, and $95.8 \%$ black. Demographic characteristics of refusers were similar to those of participants. From March 2003 to August 2003, 227 patients were approached at clinic B, 204 (90.8\%) of whom participated. Participants at clinic B were mean age 27.6 years, $41.8 \%$ male, and $91.8 \%$ black, and those refusing were similar. Differences between clinics A and B in mean age and proportion who were male were statistically significant $(\mathrm{p}=0.002$ and $\mathrm{p}=0.001$, respectively $)$.

\section{Patient satisfaction}

Overall, patients at both clinics were satisfied with healthcare service delivery (table 1). Few patients had problems obtaining care (13\% clinic A, 15\% clinic B), and almost all patients reported that office staff was helpful and courteous. Similarly, almost all patients reported that the treating clinician listened, showed respect, and spent enough time with them (greater than $98 \%$ for each measure at each clinic).

Patient satisfaction measures were high for overall clinician rating (table 1). A significantly greater proportion of patients at clinic B rated their clinician's technical skills higher that those at clinic A. Conversely, a significant proportion of patients at clinic B $(42 \%)$ rated the waiting rooms as "poor" compared to only $13 \%$ of patients at clinic A ( $p<0.001$, table 1$)$. Overall health care was rated as "poor, fair, or good" by $21 \%$ of clinic A patients and $16 \%$ of clinic B patients. Mean variance inflation factor for patient satisfaction measures was 1.44, and ranged from 1.17-1.70, indicating lack of multicollinearity.

\section{Factors associated with lower overall healthcare rating}

At clinic A, factors associated with an overall health care rating of "poor, fair, or good" at the p $<0.05$ level from exploratory analysis were: total time spent in clinic, degree that symptoms were bothersome, pain score $>1$, pruritis, previous visit to clinic A or clinic B, time spent waiting, problems getting care, whether or not the office staff was helpful or respectful, whether or not the clinician spent enough time, and all patient satisfaction measures listed in table 1 except return to clinic for future care. In univariate logistic regression, all variables were statistically significant $(\mathrm{p}<0.05)$ except total time spent in clinic, pruritis, degree that symptoms were bothersome, and whether office staff were helpful or clinician spent enough time. In multivariate logistic regression, lower rating of clinician technical skills, waiting room, and clinic environment were associated with an increased risk of lower healthcare rating, while higher clinician rating was associated with a decreased risk of lower healthcare rating (table 2 ).

At clinic B, factors associated with a lower overall healthcare rating at the $\mathrm{p}<0.05$ level from exploratory analysis were dysuria, pain score $>1$, problems with paperwork, whether office staff were helpful or the clinician explained things, receiving written materials, overall clinician rating, and rating of convenience of clinic location, clinician technical skills, and clinic environment. In univariate logistic regression, all variables were statistically significant ( $p<0.05$ ) except whether office staff were helpful and problems with paperwork. In multivariate logistic regression, lower rating of clinician technical skills and clinic environment was associated with increased risk of lower healthcare

Table 3 Results of multivariate analysis: factors associated with clinician rating less than "10"

\begin{tabular}{|c|c|c|c|c|}
\hline & \multicolumn{2}{|l|}{ Clinic A ( $n=212$ ) } & \multicolumn{2}{|l|}{ Clinic B $(n=204)$} \\
\hline & OR $(95 \% \mathrm{Cl})$ & p Value & OR $(95 \% \mathrm{Cl})$ & p Value \\
\hline $\begin{array}{l}\text { Pain score }>1 \\
\text { Any problem getting care" } \\
\text { Received written materials } \\
\text { Clinician technical skills rated "poor, } \\
\text { fair, good" } \dagger \\
\text { Overall health care rated "poor, fair, } \\
\text { good" } \\
\text { Cleanliness/comfortableness of clinic } \\
\text { rated "poor, fair, good" } \dagger\end{array}$ & $\begin{array}{l}2.48(1.31 \text { to } 4.73) \\
3.11(1.11 \text { to } 8.76) \\
0.46(0.24 \text { to } 0.89) \\
3.10(1.28 \text { to } 7.51) \\
2.54(1.04 \text { to } 6.19)\end{array}$ & $\begin{array}{l}0.006 \\
0.031 \\
0.022 \\
0.012 \\
0.040\end{array}$ & $\begin{array}{l}12.8(3.66 \text { to } 45) \\
2.10 \text { (1.09 to } 4.01)\end{array}$ & $\begin{array}{l}<0.001 \\
0.026\end{array}$ \\
\hline
\end{tabular}


rating, as was presence of dysuria (table 2). In models of data from clinics A and B, there were no statistically significant interaction terms.

\section{Factors associated with overall clinician rating}

At clinic A, factors associated with a clinician rating less than " 10 " at the $\mathrm{p}<0.05$ level from exploratory analysis were: waiting time, degree that symptoms were bothersome, pain score $>1$, problems getting care, receiving written materials, receiving medications, having an oral specimen taken, convenience of clinic location, clinician's technical skills, clinic environment, and overall health care. In univariate logistic regression, all variables were significant $(p<0.05)$ except clinic environment rating. In multivariate logistic regression, pain score $>1$, problems getting care, and lower rating of clinician technical skills and overall health care were associated with lower clinician rating, while receiving written materials had a decreased risk of lower clinician rating (table 3).

At clinic B, factors associated with a clinician rating less than " 10 " at the $\mathrm{p}<0.05$ level from exploratory analysis were: rating of clinic B service at a previous visit, whether or not the clinician explained things or spent enough time, and rating of the television and video in the waiting room, clinician's technical skills, clinic environment, and overall health care. In univariate logistic regression, only patient rating of the waiting room, clinician's technical skills, clinic environment, and overall health care were statistically significant. In multivariate logistic regression, clinician's technical skills and clinic environment rating were associated with lower clinician rating (table 3 ). In models of data from clinics A and $\mathrm{B}$, there were no statistically significant interaction terms.

\section{DISCUSSION}

Overall patient satisfaction with our public STD clinic health care was high, but varied by specific measures. Service delivery was rated very high, and results did not indicate significant areas to target for improvement. No demographic measures were associated with overall or clinician rating at either of the clinics. Patient rating of clinician technical skills and clinic environment were important determinants of satisfaction. Although "technical skills" of clinician were explained in the survey as "thoroughness, carefulness, competence," determination of specific components of patient perception of clinician technical skills will be necessary to improve overall patient satisfaction.

Distribution of written materials was a meaningful component of care in our sample. These typically include educational literature related to the specific STD condition treated, as well as a checklist of tests performed and results pending to fully inform the patient on follow up care. Clinic A and $\mathrm{B}$ patients who received written materials rated their clinician and overall health care higher. Greater satisfaction with discharge instructions was associated with greater compliance filling prescriptions among emergency department patients, ${ }^{13}$ and lower mortality among hospitalised patients. ${ }^{14}$

In a multisite study of 2490 public STD clients, 68\% said they would prefer STD clinic care in the future. ${ }^{15}$ Factors associated with returning to the STD clinic in the future were previous attendance at the STD clinic, private insurance or Medicaid coverage, and lack of primary care. These findings differ from ours. We have not found other comparative published literature, despite the potential importance of patient satisfaction with STD care.

Our study had some limitations. Our measures of satisfaction were derived from validated survey instruments (CAHPS, VRQ), but their interpretation by STD clinic patients is untested and our data demonstrate significant ceiling

\section{Key messages}

- Patient, provider, and clinic correlates of satisfaction with care in public STD clinics have not been comprehensively assessed

- Assessing public STD clinic patient satisfaction identifies aspects of care that may be improved and provides an accountability measure for responsible oversight

effects. There are additional unmeasured factors that affect patient satisfaction with care: expectations before visit, mental illness, life satisfaction, co-morbidities, and provider characteristics. ${ }^{16-18}$ The link shown between patient satisfaction and other health outcomes may not be applicable to STD outcomes. Nevertheless, systematically measuring public STD clinic patient satisfaction identifies aspects of care that may be improved and provides an accountability measure for responsible oversight. This study had a large sample size, a high patient participation rate, and collected data from a population not previously assessed in currently available literature.

We identified several specific aspects of care that may be easily altered to improve patient satisfaction with care. Relatively superficial features of the environment and clinic facility were associated with patient satisfaction: cleanliness and comfort of the clinic, television and video in the waiting room, and distribution of written materials. Future quality control may involve examining specific problems with getting care, and increasing awareness of and response to patient pain and discomfort.

Prevention of re-infection and of ongoing STD transmission depends on patient cooperation with partner notification and referral activities, as well as changing long term behaviour to prevent new STD acquisition. The link between patient satisfaction with the clinical encounter may impact the success of prevention outcomes and should be evaluated more thoroughly. Results from our study indicate a need to examine whether the outcomes of treatment adherence, partner referral, re-infection rates, and behaviour change vary by patient satisfaction and can be improved by satisfaction with health care and clinician.

\section{ACKNOWLEDGEMENTS}

We thank Ms Elizabeth Lee and Mr David Lee for data collection, and the staffs of the Baltimore City Health Department Eastern Health District and Druid Health District STD clinics. Dr Zenilman was supported by NIH grant K24AI01633.

\section{CONTRIBUTORS}

SDM originated the objective of the study, assisted with study design and selection of study measurements, developed and conducted statistical analysis, and wrote the first draft of manuscript; JMZ assisted with study design and selection of study measurements, interpretation of study results, and critical review and revision of manuscript; EJE directed and ensured integrity of data collection efforts at clinics, assisted with study design and selection of study measurements, assisted interpretation and presentation of data analysis and results, and critical review and revision of manuscript.

\section{Authors' affiliations}

S D Mehta, Boston University School of Medicine, Department of Emergency Medicine, Boston, MA, USA

J M Zenilman, E J Erbelding, The Johns Hopkins University School of Medicine, Department of Medicine, Baltimore, MD, USA

E J Erbelding, Baltimore City Health Department, Baltimore, MD, USA 


\section{REFERENCES}

1 Moore JD, Saywell RM, Thakker N, et al. An analysis of patient compliance with nurse recommendations from an after-hours call center. Am J Manag Care 2002; $8: 343-51$

2 O'Malley AS, Forrest CB, Mandelblatt J. Adherence of low-income women to cancer screening recommendations. J Gen Intern Med 2002;17:144-54.

3 Murphy DA, Roberts KJ, Martin DJ, et al. Barriers to antiretroviral adherence among HIV-infected adults. AIDS Patient Care STDS 2000;14:47-58.

4 Albright TL, Parchman M, Burge SK. RRNeST Investigators. Predictors of selfcare behavior in adults with type 2 diabetes: an RRNeST study. Fam Med 2001;33:354-60.

5 Harris LE, Luff FC, Rudy DW, et al. Correlates of health care satisfaction in inner-city patients with hypertension and chronic renal insufficiency. Soc Sci Med 1995;41:1639-45

6 Narayan KM, Gregg EW, Fagot-Campagna A, et al. Relationship between quality of diabetes care and patient satisfaction. J Natl Med Assoc 2003:95:64-70.

7 Hillis SD, Coles FB, Litchfield B. Doxycycline and azithromycin for prevention of chlamydial persistence or recurrence one month after treatment in women. A use-effectiveness study in public health settings. Sex Transm Dis 1998:25:5-11.

8 Bachmann L, Stevens J, Richey C, et al. Measured versus self-reported compliance for doxycycline therapy for chlamydia-associated syndromes: high therapeutic success rates despite poor compliance. Sex Transm Dis 1999;26:272-8

9 Ware JE Jr, Sherbourne CD. The MOS 36-item short-form health survey (SF36). I. Conceptual framework and item selection. Med Care 1992;30:473-83.
10 Melzack R The short-form McGill Pain Questionnaire. Pain 1987;30:191-7.

11 Agency for Health Care Policy and Research. Consumer Assessments of Health Plans Study (CAPHS). CAHPS 2.0 Adult Core Questionnaire. Rockville, MD: Agency for Health Care Policy and Research. Accessed 4 January 2002 from www.ahrq.gov/qual/cahps/ on.

12 Rubin HR, Gandek B, Rogers WH, et al. Patients' ratings of outpatient visits in different practice settings: results from the Medical Outcomes Study. JAMA 1993;270:835-40

13 Thomas EJ, Burstin HR, O'Neil AC, et al. Patient noncompliance with medical advice after the emergency department visit. Ann Emerg Med 1996;27:49-55.

14 Jaipaul CK, Rosenthal GE. Do hospitals with lower mortality have higher patient satisfaction? A regional analysis of patients with medical diagnoses. Am J Med Qual 2003;18:59-65.

15 Celum CL, Bolan G, Krone M, et al. Patients attending STD clinics in an evolving health care environment. Demographics, insurance coverage, preferences for STD services, and STD morbidity. Sex Transm Dis 1997;24:599-605.

16 Sullivan LM, Stein MD, Savetsky JB, et al. The doctor-patient relationship and HIV-infected patients' satisfaction with primary care physicians. J Gen Intern Med 2000; 15:462-9.

17 Kerr EA, Smith DM, Kaplan SH, et al. The association between three different measures of health status and satisfaction among patients with diabetes. Med Care Res Rev 2003:60:158-77.

18 Jackson JL, Kroenke K. The effect of unmet expectations among adults presenting with physical symptoms. Ann Intern Med 2001;134:889-97. 